\title{
Outpatient Management of Chronic Obstructive Pulmonary Disease: Physician Adherence to the 2017 Global Initiative for Chronic Obstructive Lung Disease Guidelines and Its Effect on Patient Outcomes
}

\author{
Brian Chinaia, d, Krystal Hunter ${ }^{\mathrm{b}, \mathrm{c}}$, Satyajeet Roy ${ }^{\mathrm{a}, \mathrm{c}}$
}

\begin{abstract}
Background: Chronic obstructive pulmonary disease (COPD) is a common and preventable illness that carries significant economic and social burden. The Global Initiative for Chronic Obstructive Lung Disease (GOLD) provides a comprehensive review of the available literature for the diagnosis and management of COPD. Despite being considered the standard of care, adherence to the GOLD guidelines varies among practitioners. In addition, there is yet to be a clear correlation between misalignment with GOLD practicing guidelines and patient outcomes. We studied the outpatient management of COPD, with special attention paid to whether or not adherence to the 2017 GOLD guidelines affected patient outcomes.
\end{abstract}

Methods: This retrospective electronic medical record review study observed the outpatient management of patients with COPD, aged 18 year or older, who presented to the suburban primary care office. Patients who received treatment according to the GOLD guidelines were compared with the patients who did not. Categorical data were analyzed as frequencies with percentages. Frequencies were compared using Chi-square and Fisher's exact tests. A P value $<0.05$ was used to determine statistical significance.

Results: A total of 158 patients were included in this study. Thirty-six percent of the patients were treated according to the GOLD guidelines. There was no significant difference in the mortality, exacerbations or hospitalizations between the patients who were treated according to the GOLD guidelines and those who were not. Comparing prescribing practices for those treated according to the GOLD guidelines versus those who were not, a significant difference in management occurred in regards to long acting beta agonist $(\mathrm{P}<0.05)$ and

Manuscript submitted May 28, 2019, accepted June 17, 2019

a Department of Internal Medicine, Cooper University Healthcare, Camden, NJ, USA

${ }^{\mathrm{b}}$ Cooper Research Institute, Cooper University Healthcare, Camden, NJ, USA ${ }^{\mathrm{c} C o o p e r}$ Medical School at Rowan University, Camden, NJ, USA

${ }^{\mathrm{d} C}$ Corresponding Author: Brian Chinai, Cooper University Healthcare, 1103

North Kings Highway, Suite 203, Cherry Hill, NJ 08034, USA.

Email: Chinai-brian@cooperhealth.edu

doi: https://doi.org/10.14740/jocmr3888 inhaled corticosteroid therapy $(\mathrm{P}<0.001)$. The differences in the use of other pharmacological and nonpharmacological agents were not significant.

Conclusions: Adherence to the 2017 GOLD guidelines had no statistically significant difference in patient outcomes. GOLD nonadherent patients received long-acting beta agonist and inhaled corticosteroid therapy at a significantly higher frequency compared to GOLD-adherent patients.

Keywords: COPD; 2017 GOLD guidelines; Outpatient management

\section{Introduction}

Chronic obstructive pulmonary disease (COPD) is a common and preventable illness that carries a significant economic and social burden. Current economic data shows that in the United States, COPD is the responsible for approximately $\$ 52$ billion in direct and indirect healthcare costs [1]. The Burden of Obstructive Lung Disease (BOLD) program and other large epidemiologic studies approximate that 384 million individuals are affected, estimating a global prevalence of $11.7 \%$ [2]. However, COPD remains largely underdiagnosed, likely due to differences in diagnostic criteria and patient presentation [3]. Currently, it is the fourth leading cause of death worldwide, with an estimated 3 million deaths annually $[4,5]$. Epidemiologic trends have estimated that COPD will climb to third by the year 2020 , thereby claiming approximately 4.5 million deaths annually $[6,7]$. This increase in prevalence is attributable to the aging population and the increased incidence of smoking worldwide [6].

COPD is a disease characterized by incompletely reversible airway obstruction [8]. It is further defined as the combination of small airway disease and parenchymal destruction that leads to the hallmark airflow limitation. Exposure to noxious particles and gases causes chronic airway inflammation, resulting in airway remodeling. Chronic lung injury and subsequent repair leads to structural lung changes, such as airway narrowing, wall thickening, and loss of alveolar attachments, thus causing decreased lung elasticity and the parenchymal de- 
struction that is pathologically consistent with emphysema [9]. These structural lung changes also result in the chronic respiratory symptoms associated with COPD, including dyspnea, wheezing, chest tightness, and cough with or without sputum production.

The most common risk factor for COPD remains smoking; however, studies show that this is an association rather than a causal relationship [9]. Cigarette smoking is associated with a higher prevalence of pulmonary symptoms, a greater reduction in the forced expiratory volume in the first second (FEV1) and a greater mortality in patients with COPD [10]. Another significant risk factor for the development of COPD is a history of asthma. A long-term longitudinal study of patients with asthma found that $20 \%$ of the studied asthmatics developed irreversible airflow obstruction, while another report found that asthmatics had a 12-fold higher risk of developing COPD compared to non-asthmatics $[11,12]$. Occupational exposures also play a role in the development of COPD. A large-scale National Health and Nutrition Examination Survey estimated that the fraction of COPD attributable to workplace exposure was $19.2 \%$ in smokers and $31.1 \%$ in nonsmokers [13]. Other risk factors include age, genetics, socioeconomic status, and lung growth and development. Previously, it used to be believed that males were predisposed to developing COPD, but recent studies have shown an almost even gender distribution [14].

The airflow limitation that is the hallmark of COPD can be diagnosed via pulmonary function tests (PFTs) in patients who present with symptoms and risk factors concerning for the disease. PFTs are a reproducible and objective measurement of airflow obstruction. The Global Initiative for Chronic Obstructive Lung Disease (GOLD) guidelines of 2017 define COPD as the ratio of the forced expiratory volume in one second and the forced vital capacity $(\mathrm{FEV} 1 / \mathrm{FVC})<0.7$ postbronchodilator administration [9]. They further characterize the severity of the disease by the reduction in FEV1. The modified Medical Research Council (mMRC) dyspnea scale and COPD Assessment Test (CAT) are then commonly used to assess the severity of a patient's symptoms. These three tests, along with exacerbation risk, are used in the GOLD guidelines to classify patients in one of the four stages that guide the optimal treatment. The GOLD 2017 guidelines also provide specific algorithms for the treatment of each stage and the modifications that can be made if patients' symptoms are poorly controlled.

Although the GOLD guidelines are considered a comprehensive review of the literature available for the diagnosis and management of COPD, adherence to the criteria varies among practitioners. One cross sectional survey evaluating the management of more than 1,500 COPD patients in multiple countries found that adherence to the GOLD 2014 criteria varied across the GOLD stages, with the lowest rates being seen in stage B patients [15]. In the same study, the investigators also found that, in general, the vast majority of patients reported a high symptom burden, thus suggesting misalignment of practicing with GOLD recommendations [15]. Another report looking at prescribing practices over a 5 -year period found that medications prescribed to COPD patients correlated not with the GOLD treatment guidelines, but instead with the number of health care visits [16].

Although these studies describe prescribing tendencies, they pertain to previous iterations of the GOLD guidelines. Very little data has been published describing whether adherence to the GOLD guidelines has improved with the 2017 updates. Many COPD patients have significant disease burden; however, there is yet to be a clear correlation between misalignment with GOLD practicing guidelines and increased patient morbidity and mortality. We designed this study to examine the outpatient management of COPD while paying special attention to whether or not adherence to the 2017 GOLD guidelines affected patient outcomes.

\section{Materials and Methods}

\section{Study selection}

This study was a retrospective electronic medical record review that observed the outpatient management of patients with COPD. Patients were seen in a single suburban primary care office between January 1, 2017 and December 31, 2017. The inclusion criteria were patients aged 18 and older who presented to the office during the time period with a documented diagnosis of COPD in the electronic medical record. The exclusion criteria were patients under the age of 18 years, who had no diagnosis of COPD, or who had another pulmonary disorder(s). This study was reviewed and approved by the Institutional Review Board at Cooper University Hospital and was conducted in compliance with all the applicable ethical standards of the institution.

\section{Data collection}

The following data were collected for each patient: age, gender (male or female), race (Caucasian, African American, Asian, or Other), body mass index, history of cigarette smoking, documented diagnosis of COPD or emphysema, spirometry confirming diagnosis of COPD, FEV1, FEV1/FVC ratio, carbon monoxide diffusion capacity (DLCO), outpatient pulmonary follow-up, and comorbid medical conditions, such as atherosclerotic cardiovascular disease, hypertension, hyperlipidemia, diabetes mellitus, allergic and immunological disorders, malignancy, immunodeficiency, thyroid conditions, gastrointestinal disorder, polycythemia, other hematological illnesses, central nervous system disorders, obstructive sleep apnea and chronic kidney disease stage 3 to 5 . Additional data included the number of exacerbations and hospitalizations in the preceding year, COPD assessment test score, Modified Medical Research Council dyspnea score, medication management (short acting beta agonist (SABA), long acting beta agonist (LABA), short acting antimuscarinic agent (SAMA), long acting antimuscarinic agent (LAMA), inhaled corticosteroid (ICS), roflumilast, oral corticosteroid, home oxygen therapy, and oral antibiotic), use of home oxygen therapy, pulmonary rehabilitation, GOLD management category, adherence to GOLD recommendations and mortality. 


\section{Statistical analysis}

Data were collected and entered into a Microsoft Excel spreadsheet (2016, Redmond, Washington, USA). Statistical analysis was carried out using SPSS software (IBM Corporation, Armonk, New York, USA). Categorical data were analyzed as frequencies with percentages and continuous data were analyzed as means with standard deviations. Frequencies were compared using Chi-square and Fisher's exact tests. Logistic regression models were used to determine if the variables had a significant relationship with mortality, number of exacerbations per year and disease progression. A P value $<0.05$ was used to determine statistical significance.

\section{Results}

A total of 158 patients were included in this study. The mean age of patients was $71.58 \pm 12.9$. The majority of the patients were female (55.7\%) (Table 1). The mean body mass index of the patients was $27.61 \pm 6.67 \mathrm{~kg} / \mathrm{m}^{2}$. The majority of patients were white $(77.2 \%)$, followed by black (13.3\%), Asian (5.1\%) and Hispanic (4.4\%). The majority (96.2\%) of the patients had a history of smoking and $94.9 \%$ had a documented diagnosis of COPD at time of presentation. On the other hand, only twothirds $(65.2 \%)$ of patients had evidence of emphysema on radiography. Of the 158 patients in this study, $56.3 \%$ of patients had spirometric confirmation of the diagnosis, and $55.7 \%$ had pulmonary follow-up. The patients who had pulmonary follow-up were more likely to have documentation of spirometric diagnosis of COPD compared to the patients who did not have pulmonary follow-up $(78.4 \%$ vs. $25.7 \%$; $\mathrm{P}<0.001)$. We were able to classify patients according to the GOLD guidelines in $56.3 \%$ of the patients. Thirty-six percent of these patients were treated based on the GOLD guidelines while $64 \%$ were not.

The majority of patients in our study were treated with SABA (90.5\%), followed by LABA $(56.3 \%)$ and ICS (54.4\%) (Table 2). A LAMA was prescribed to about two-fifths of the patients $(41.1 \%)$. About a quarter $(24.1 \%)$ of the patients were on home oxygen therapy. Only $11.4 \%$ of patients were referred to pulmonary rehabilitation. For those patients treated accord-
Table 1. Demographic and Clinical Characteristics

\begin{tabular}{|c|c|}
\hline Variable & Frequency $(n=158)$ \\
\hline Age (years, mean (SD)) & $71.58(12.9)$ \\
\hline Body mass index $\left(\mathrm{kg} / \mathrm{m}^{2}\right.$, mean $\left.(\mathrm{SD})\right)$ & $27.61(6.67)$ \\
\hline \multicolumn{2}{|l|}{ Gender } \\
\hline Male, n (\%) & $70(44.3)$ \\
\hline Female, n (\%) & $88(55.7)$ \\
\hline \multicolumn{2}{|l|}{ Race } \\
\hline White, n (\%) & $122(77.2)$ \\
\hline Black, n (\%) & $21(13.3)$ \\
\hline Asian, n (\%) & $8(5.1)$ \\
\hline Hispanic, n (\%) & $7(4.4)$ \\
\hline \multicolumn{2}{|l|}{ Social } \\
\hline Smoking (n, \%) & $152(96.2)$ \\
\hline \multicolumn{2}{|l|}{ Diagnosis } \\
\hline COPD (n, \%) & $150(94.9)$ \\
\hline Emphysema (n, \%) & $103(65.2)$ \\
\hline Pulmonary follow-up (n, \%) & $88(55.7)$ \\
\hline \multicolumn{2}{|l|}{ Spirometric diagnosis } \\
\hline COPD (n, \%) & $89(56.3)$ \\
\hline Pulmonary follow-up (n, \%) & $69(78.4)$ \\
\hline No pulmonary follow-up (n, \%) & $20(21.6)$ \\
\hline GOLD criteria calculated (n, \%) & $89(56.3)$ \\
\hline Management per GOLD (n, \%) & $32(36.0)$ \\
\hline Management not per GOLD (n, \%) & $57(64.0)$ \\
\hline
\end{tabular}

SD: standard deviation; COPD: chronic obstructive pulmonary disease; GOLD: Global Initiative for Obstructive Lung Disease.

ing to the GOLD guidelines, $87.5 \%$ received SABA, $50.0 \%$ received LAMA, $46.9 \%$ received LABA, $25.0 \%$ received ICS and $25.0 \%$ were on home oxygen therapy. For those patients who were not treated according to the GOLD guidelines, $96.5 \%$ received SABA, $73.7 \%$ received ICS, $70.2 \%$ re-

Table 2. Management of COPD

\begin{tabular}{lllll}
\hline Variable & $\begin{array}{l}\text { All frequency } \\
(\mathbf{n}=\mathbf{1 5 8})\end{array}$ & $\begin{array}{l}\text { GOLD frequency } \\
(\mathbf{n = 3 2})\end{array}$ & $\begin{array}{l}\text { No GOLD frequency } \\
(\mathbf{n = 5 7 )}\end{array}$ & $\begin{array}{l}\text { P value (GOLD } \\
\text { vs. No GOLD) }\end{array}$ \\
\hline SABA (n, \%) & $143(90.5)$ & $28(87.5)$ & $55(96.5)$ & 0.183 \\
\hline LABA (n, \%) & $89(56.3)$ & $15(46.9)$ & $40(70.2)$ & $<0.05$ \\
SAMA (n, \%) & $12(7.6)$ & $4(12.5)$ & $3(5.3)$ & 0.246 \\
LAMA (n, \%) & $65(41.1)$ & $16(50.0)$ & $28(49.1)$ & 0.937 \\
ICS (n, \%) & $86(54.4)$ & $8(25.0)$ & $42(73.7)$ & $<0.001$ \\
Roflumilast (n, \%) & $1(0.6)$ & $0(0)$ & $1(1.8)$ & 1.000 \\
Home oxygen therapy (n, \%) & $38(24.1)$ & $8(25.0)$ & $7(33.3)$ & 0.412 \\
Pulmonary rehabilitation (n, \%) & $18(11.4)$ & $9(28.1)$ & $7(12.3)$ & 0.062 \\
\hline
\end{tabular}

SABA: short acting beta agonist; LABA: long acting beta agonist; SAMA: short acting antimuscarinic agent; LAMA: long acting antimuscarinic agent; ICS: inhaled corticosteroid. 
Table 3. Patient Outcomes

\begin{tabular}{lllll}
\hline Variable & $\begin{array}{l}\text { All frequency } \\
(\mathbf{n}=\mathbf{1 5 8})\end{array}$ & $\begin{array}{l}\text { GOLD frequency } \\
(\mathbf{n = 3 2})\end{array}$ & $\begin{array}{l}\text { No GOLD frequency } \\
(\mathbf{n}=\mathbf{5 7})\end{array}$ & $\begin{array}{l}\text { P value (GOLD } \\
\text { vs. No GOLD) }\end{array}$ \\
\hline Oral corticosteroid & $77(48.7)$ & $14(43.8)$ & $37(64.9)$ & 0.053 \\
Oral antibiotic & $73(46.2)$ & $16(50.0)$ & $32(56.1)$ & 0.577 \\
Increase in home $\mathrm{O}_{2}$ & $16(10.1)$ & $6(18.8)$ & $7(12.3)$ & 0.407 \\
Mortality & $15(9.5)$ & $4(12.5)$ & $7(12.3)$ & 1.000 \\
\hline
\end{tabular}

ceived LABA, 49.1\% received LAMA, and 33.3\% were on home oxygen therapy. More patients received LABA and ICS therapy in the group who were not treated according to the GOLD guidelines compared to the patients who were treated according to the GOLD guidelines. These therapeutic differences were statistically significant in regards to LABA $(\mathrm{P}<$ $0.05)$ and ICS therapy $(\mathrm{P}<0.001)$. The differences in the use of other pharmacologic and non-pharmacologic therapies were not statistically significant between the two groups.

The mortality rate was $9.5 \%$ among all the patients in our study. Patients treated according to the GOLD guidelines had a mortality rate of $12.5 \%$, while those not treated according to the GOLD guidelines had a mortality rate of $12.3 \%$ (Table 3 ). There was no statistically significant difference in mortality between the two groups. About half of all the patients $(48.7 \%)$ required oral corticosteroids during the 1-year period and $46.2 \%$ required oral antibiotics. Although a higher number of patients who were not treated according to the GOLD guidelines required oral corticosteroids during the 1-year period $(64.9 \%)$ compared to the $43.8 \%$ of patients treated according to the GOLD guidelines, the difference was not statistically significant $(\mathrm{P}=0.053)$. Half of the patients treated according to the GOLD guidelines $(50 \%)$ received oral antibiotics compared to $56.1 \%$ patients who were not treated according to the GOLD guidelines. The difference was not statistically significant. The patients who were not treated according to the GOLD guidelines had a larger distribution of exacerbations compared to the patients treated according to the GOLD guidelines (Fig. 1), but the outcome data were not statistically significant $(\mathrm{P}=0.082)$.

\section{Discussion}

COPD carries significant social and economic burden. Epidemiologic studies have shown that the incidence and mortality of COPD are increasing [4-7]. While much of this is due to the aging population and the increased incidence of smoking worldwide, new guidelines are routinely published to assist in the management of COPD in the hopes of preventing a similar trend in morbidity and mortality. The GOLD guidelines were updated in 2017 to provide a more comprehensive blueprint for the diagnosis and management of COPD. While it is considered the standard of care, the adherence to the previous iterations of these guidelines varies greatly among healthcare practitioners $[15,16]$.

In our study, approximately one-third $(36 \%)$ of the patients staged according to the GOLD criteria received therapy according to the GOLD guidelines, which falls in line with the previous iterations of the GOLD guidelines [17-21]. Nonadherence to the GOLD prescribing guidelines likely occurs for a variety of reasons. An important initial consideration is the low physician awareness of evolving guidelines and the associated gaps in knowledge regarding the diagnosis and treatment of COPD [22]. One cross sectional study found that, in their cohort, only approximately one-third of physicians knew the GOLD criteria [23]. Along the same lines, Li and associates demonstrated that approximately $55 \%$ of general practitioners recognized the GOLD criteria, yet only $8 \%$ of patients received therapy in accordance with the GOLD guidelines [24]. It is important to also mention that a survey of primary care physicians in New York reported that low self-efficacy and physician time constraints played a major role in GOLD nonadherence [25]. Current literature does not prove that lack of perceived benefit or disagreement with the guidelines are potential barriers to adherence to the GOLD criteria. While there are physician-related barriers to GOLD adherence, there are also patient-related factors to mention as well. Symptomatology and exacerbation rates, as opposed to objective spirometric criteria, are significant drivers of patient management $[17,26]$.

Our cohort demonstrated no significant difference in patient outcomes when comparing GOLD-adherent versus

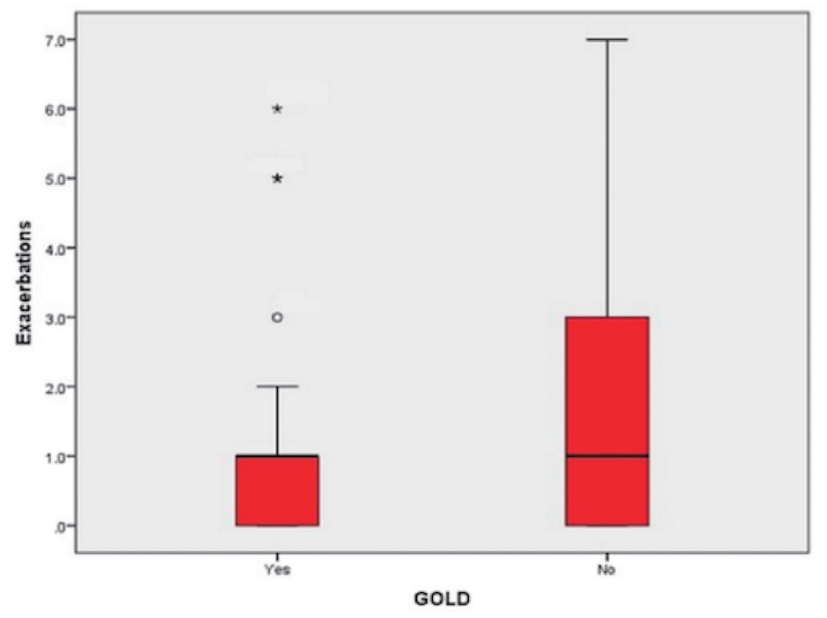

Figure 1. Comparison of the distribution of exacerbations for patients treated according to the GOLD guidelines $(n=32)$ versus those who were not $(n=57)$. GOLD-adherent patients had outliers in their distribution of exacerbations. The star represents one subject who experienced six exacerbations during the 1-year period. The asterisk represents two subjects who experienced five exacerbations. The circle represents one subject who experienced three exacerbations. 
GOLD non-adherent management. A potential explanation for this may be that, as mentioned above, prescribers advance COPD therapy based on symptoms, functional status and exacerbation risk, as opposed to spirometric data. Therefore, patients may be overtreated, especially in light of growing evidence that the use of triple therapy may result in lower exacerbation risk, fewer hospitalizations, improved lung function and better quality of life $[27,28]$.

The available literature studying the effects of GOLD adherence offers conflicting data, although little is currently known in regards to the 2017 guidelines. In a large-scale study, Mannino and associates found that patients treated according to the 2011 GOLD guidelines had a benefit in nearly all outcomes, including COPD-related symptoms, emergency department visits and hospitalizations [17]. Conversely, Jochmann and associates found that guideline adherence did not significantly affect exacerbation rates, symptoms, or lung function decline [29]. While outcomes may vary between cohorts, longer term studies are needed to truly ascertain the true effect of adherence to the GOLD guidelines.

Interestingly, our study found that there was a significant difference in the use of ICS when comparing GOLD adherent versus GOLD non-adherent management $(\mathrm{P}<0.001)$. The GOLD non-adherent patients were three times more likely to be prescribed an ICS. Current guidelines state that an ICS should be added to regular bronchodilator therapy in COPD patients with severe airflow limitation and/or frequent exacerbations [30]. Despite these guidelines, Izquierdo and associates found that ICS are widely prescribed to all stages of COPD patients [31]. The overuse of ICS may be due to practitioners starting patients on ICS/LABA or triple therapy to cover both asthma and COPD, as there is often a lack of spirometry differentiating the two diagnoses [32].

In our cohort, $56.3 \%$ of patients were diagnosed with COPD using spirometry. We demonstrate a higher use of spirometry when compared to the existing literature, although much improvement is still to be made. Two large retrospective studies demonstrated that spirometry was only used for approximately one-third of newly diagnosed COPD patients $[33,34]$. Another study showed that only $32 \%$ of their cohort had spirometric diagnosis of COPD, but expanded further by stating that the use of testing decreased with increasing age [35]. The likely explanation for the low usage of spirometry is that many patients come to primary care practices with a documented diagnosis of COPD without spirometric confirmation and physicians then conclude the patients' COPD diagnoses based on their clinical examination and the patients' history of smoking. It is unclear whether lack of knowledge regarding, or the attitude towards the utility of, spirometry affects clinician use [34]. Despite spirometry being the gold standard tool to establish the diagnosis and the degree of airflow limitation, the variability in its use makes us vulnerable to misdiagnosis and inappropriate treatment [36].

Unsurprisingly, patients who followed with a pulmonologist were approximately four times more likely to have spirometric diagnosis of COPD $(\mathrm{P}<0.001)$. This is consistent with previous studies, one of which demonstrated that use of spirometry was 3.3 times higher for patients following with pulmonologists [34]. It is currently unclear exactly why this is the case, but this finding likely underscores the importance of referring potential COPD patients to pulmonologists for further workup and management.

Based on our literature review, there is little data analyzing adherence to the 2017 iteration of the GOLD guidelines and its effect on patient outcomes. Therefore, to the best of our knowledge, our study is the first to take an in-depth look into the adherence of the 2017 GOLD guidelines and its effect on outcomes.

The major strength of our study was establishing a strictly narrow range of inclusion criteria so as to exclude patients with potential confounding comorbidities that might have impacted outcomes of their COPD management.

There were several limitations to our study that need to be mentioned. This retrospective electronic medical record review was limited to a single outpatient suburban primary care office, therefore limiting its generalizability. Our study period lasted for 12 months, thus limiting our ability to draw conclusions regarding long-term COPD care. Similarly, limitation of documentation of confounding factors in the electronic medical records, such as socioeconomic status, insurance status, living situation, etc., limited our ability to analyze the influence of such factors in patient outcomes.

We conclude that adherence to the 2017 GOLD guidelines had no statistically significant difference in patient outcomes. However, GOLD non-adherent patients received LABA and ICS therapy at a significantly higher frequency compared to GOLD-adherent patients. Further studies are needed examining long-term practicing guidelines at multiple institutions nationwide.

\section{Acknowledgments}

The authors thank Christine Rickette, RN (study coordinator) for her contribution to this study.

\section{Financial Disclosure}

None to declare.

\section{Conflict of Interest}

None to declare.

\section{Informed Consent}

Not applicable in this retrospective electronic medical record study.

\section{Author Contributions}

BC and SR devised the study protocol. BC collected the data and wrote the initial manuscript. $\mathrm{KH}$ provided statistical analysis of the data. SR revised the final manuscript. 


\section{References}

1. Guarascio AJ, Ray SM, Finch CK, Self TH. The clinical and economic burden of chronic obstructive pulmonary disease in the USA. Clinicoecon Outcomes Res. 2013;5:235-245.

2. Adeloye D, Chua S, Lee C, Basquill C, Papana A, Theodoratou E, Nair H, et al. Global and regional estimates of COPD prevalence: Systematic review and meta-analysis. J Glob Health. 2015;5(2):020415.

3. Mathers CD, Loncar D. Projections of global mortality and burden of disease from 2002 to 2030. PLoS Med. 2006;3(11):e442.

4. Lozano R, Naghavi M, Foreman K, Lim S, Shibuya K, Aboyans V, Abraham J, et al. Global and regional mortality from 235 causes of death for 20 age groups in 1990 and 2010: a systematic analysis for the Global Burden of Disease Study 2010. Lancet. 2012;380(9859):2095-2128.

5. Global Burden of Disease Study Collaborators, Causes of Death Collaborators. Global, regional, and national age-sex specific all-cause and cause-specific mortality for 240 causes of death, 1990-2013: a systematic analysis for the Global Burden of Disease Study 2013. Lancet. 2015;385(9963):117-171.

6. Lopez AD, Shibuya K, Rao C, Mathers CD, Hansell AL, Held LS, Schmid V, et al. Chronic obstructive pulmonary disease: current burden and future projections. Eur Respir J. 2006;27(2):397-412.

7. World Health Organization. Projections of mortality and causes of death, 2015 and 2030. 2018. (Accessed May 25, 2019, at http://www.who.int/healthinfo/global_burden_disease/projections/en/).

8. Postma DS, Rabe KF. The Asthma-COPD overlap syndrome. N Engl J Med. 2015;373(13):1241-1249.

9. Global Strategy for the Diagnosis, Management and Prevention of COPD. Global Initiative for Chronic Obstructive Lung Diseases (GOLD) 2017. (Accessed May 25, 2019, at https://goldcopd.org/wp-content/uploads/2016/12/wms-GOLD-2017-Pocket-Guide.pdf.).

10. Kohansal R, Martinez-Camblor P, Agusti A, Buist AS, Mannino DM, Soriano JB. The natural history of chronic airflow obstruction revisited: an analysis of the Framingham offspring cohort. Am J Respir Crit Care Med. 2009;180(1):3-10.

11. Vonk JM, Jongepier H, Panhuysen CI, Schouten JP, Bleecker ER, Postma DS. Risk factors associated with the presence of irreversible airflow limitation and reduced transfer coefficient in patients with asthma after 26 years of follow up. Thorax. 2003;58(4):322-327.

12. Silva GE, Sherrill DL, Guerra S, Barbee RA. Asthma as a risk factor for COPD in a longitudinal study. Chest. 2004;126(1):59-65.

13. Hnizdo E, Sullivan PA, Bang KM, Wagner G. Association between chronic obstructive pulmonary disease and employment by industry and occupation in the US population: a study of data from the Third National Health and Nutrition Examination Survey. Am J Epidemiol. 2002;156(8):738-746.
14. Landis SH, Muellerova H, Mannino DM, Menezes AM, Han MK, van der Molen T, Ichinose M, et al. Continuing to Confront COPD International Patient Survey: methods, COPD prevalence, and disease burden in 2012-2013. Int J Chron Obstruct Pulmon Dis. 2014;9:597-611.

15. Ding B, Small M, Holmgren U. A cross-sectional survey of current treatment and symptom burden of patients with COPD consulting for routine care according to GOLD 2014 classifications. Int J Chron Obstruct Pulmon Dis. 2017; 12:1527-1537.

16. Seaman J, Leonard AC, Panos RJ. Health care utilization history, GOLD guidelines, and respiratory medication prescriptions in patients with COPD. Int J Chron Obstruct Pulmon Dis. 2010;5:89-97.

17. Mannino DM, Yu TC, Zhou H, Higuchi K. Effects of GOLD-adherent prescribing on COPD symptom burden, exacerbations, and health care utilization in a real-world setting. Chronic Obstr Pulm Dis. 2015;2(3):223-235.

18. Mularski RA, Asch SM, Shrank WH, Kerr EA, Setodji CM, Adams JL, Keesey J, et al. The quality of obstructive lung disease care for adults in the United States as measured by adherence to recommended processes. Chest. 2006;130(6):1844-1850.

19. Koblizek V, Pecen L, Zatloukal J, Kocianova J, Plutinsky M, Kolek V, Novotna B, et al. Real-life GOLD 2011 implementation: the management of COPD lacks correct classification and adequate treatment. PLoS One. 2014;9(11):e111078.

20. Sharif R, Cuevas CR, Wang Y, Arora M, Sharma G. Guideline adherence in management of stable chronic obstructive pulmonary disease. Respir Med. 2013;107(7):10461052.

21. Yawn BP, Wollan PC. Knowledge and attitudes of family physicians coming to COPD continuing medical education. Int J Chron Obstruct Pulmon Dis. 2008;3(2):311317.

22. Overington JD, Huang YC, Abramson MJ, Brown JL, Goddard JR, Bowman RV, Fong KM, et al. Implementing clinical guidelines for chronic obstructive pulmonary disease: barriers and solutions. J Thorac Dis. 2014;6(11):1586-1596.

23. Rutschmann OT, Janssens JP, Vermeulen B, Sarasin FP. Knowledge of guidelines for the management of COPD: a survey of primary care physicians. Respir Med. 2004;98(10):932-937.

24. Li F, Cai Y, Zhu Y, Chen X, Xu X, Zhang X, et al. The evaluation of general practitioners' awareness/knowledge and adherence to the GOLD guidelines in a Shanghai suburb. Asia Pacific Journal of Public Health. 2015;27:20672078.

25. Perez X, Wisnivesky JP, Lurslurchachai L, Kleinman LC, Kronish IM. Barriers to adherence to COPD guidelines among primary care providers. Respir Med. 2012;106(3):374-381.

26. Foda HD, Brehm A, Goldsteen K, Edelman NH. Inverse relationship between nonadherence to original GOLD treatment guidelines and exacerbations of COPD. Int J Chron Obstruct Pulmon Dis. 2017;12:209-214.

27. Zheng Y, Zhu J, Liu Y, Lai W, Lin C, Qiu K, Wu J, et al. 
Triple therapy in the management of chronic obstructive pulmonary disease: systematic review and meta-analysis. BMJ. 2018;363:k4388.

28. Lipson DA, Barnhart F, Brealey N, Brooks J, Criner GJ, Day NC, Dransfield MT, et al. Once-daily singleinhaler triple versus dual therapy in patients with COPD. N Engl J Med. 2018;378(18):1671-1680.

29. Jochmann A, Scherr A, Jochmann DC, Miedinger D, Torok SS, Chhajed PN, Tamm M, et al. Impact of adherence to the GOLD guidelines on symptom prevalence, lung function decline and exacerbation rate in the Swiss COPD cohort. Swiss Med Wkly. 2012;142:w13567.

30. Yawn BP, Suissa S, Rossi A. Appropriate use of inhaled corticosteroids in COPD: the candidates for safe withdrawal. Primary Care Respiratory Medicine. 2016;26:19.

31. Izquierdo JL, Martin A, de Lucas P, Rodriguez-Gonzalez-Moro JM, Almonacid C, Paravisini A. Misdiagnosis of patients receiving inhaled therapies in primary care.
Int J Chron Obstruct Pulmon Dis. 2010;5:241-249.

32. Cataldo D, Derom E, Liistro G, Marchand E, Ninane V, Peche R, Slabbynck H, et al. Overuse of inhaled corticosteroids in COPD: five questions for withdrawal in daily practice. Int J Chron Obstruct Pulmon Dis. 2018;13:20892099.

33. Arne M, Lisspers K, Stallberg B, Boman G, Hedenstrom $\mathrm{H}$, Janson $\mathrm{C}$, Emtner $\mathrm{M}$. How often is diagnosis of COPD confirmed with spirometry? Respir Med. 2010;104(4):550-556.

34. Lee TA, Bartle B, Weiss KB. Spirometry use in clinical practice following diagnosis of COPD. Chest. 2006;129(6):1509-1515.

35. Han MK, Kim MG, Mardon R, Renner P, Sullivan S, Diette GB, Martinez FJ. Spirometry utilization for COPD: how do we measure up? Chest. 2007;132(2):403-409.

36. Bailey KL. The importance of the assessment of pulmonary function in COPD. Med Clin North Am. 2012;96(4):745-752. 